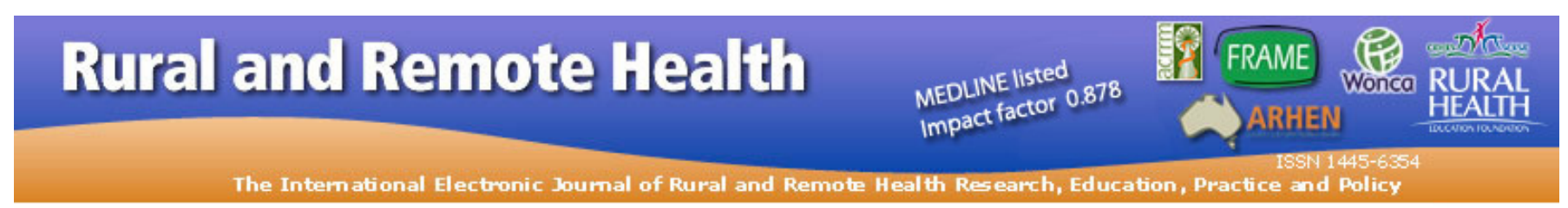

\title{
ORIG I N A RESEARCH \\ Differences in characteristics between suicide cases of farm managers compared to those of farm labourers in Queensland, Australia
}

\author{
U Arnautovska, McPhedran S, D De Leo \\ Griffith University, Mt Gravatt, Queensland, Australia
}

Submitted: 22 August 2014; Revised: 2 April 2015; Accepted: 7 May 2015; Published: 22 September 2015

Arnautovska U, S McPhedran, De Leo D

Differences in characteristics between suicide cases of farm managers compared to those of farm labourers in Queensland, Australia

Rural and Remote Health 15: 3250. (Online) 2015

Available: http://www.rrh.org.au

\section{A B S T R A C T}

Introduction: Farmers constitute an occupation group at a heightened suicide risk compared to the general population. To date, research has tried to explain this peculiarity by identifying suicide risk factors that are common to the whole of the farming population. There are, however, indications that risk factors may be different for different sub-populations of farmers, such as younger/older farmers or farm managers/farm labourers. This study compared the characteristics of suicides by farm managers and farm labourers, while controlling for the effect of age.

Methods: A review of two datasets, the Queensland Suicide Register and the National Coroners Information System, was conducted in which a total of 78 cases of farm managers and 69 cases of farm labourers were identified as a suicide during 20002009, Queensland, Australia. The main outcome measures included various demographic characteristics, circumstances related to death, health and mental health variables, and history of stressful life events.

Results: The two groups differed in marital status, living arrangements, ethnicity, physical and mental illness, alcohol and drug abuse, contact with a health professional prior to death, and specific life events such as relationship breakdown and recent/pending unemployment. The majority of these differences were not statistically significant once age was accounted for. However, differences in psychiatric variables and experience of a recent/pending unemployment remained significant.

Conclusions: This study contributes towards better understanding of suicide among farmers in different job positions, and highlights the need for tailored suicide prevention initiatives that consider a combination of age- and job-specific suicide risk and protective factors among farmers.

Key words: age effect, Australia, farmers, job position, suicide risk factors. 


\section{Introduction}

Farmers in Australia have been recognised to be at a heightened risk for suicide ${ }^{1,2}$. Similarly, suicide rates among farmers are elevated in other countries across the world, including the USA, Brazil, England, India, and New Zealand ${ }^{3-}$ 7. Possible explanations for high suicide rates in farming, and rural populations more broadly, typically include the circumstances associated with rural living conditions, such as geographic isolation ${ }^{8}$, natural disasters and financial stressors related with these disasters ${ }^{9}$, and other economic and sociopolitical factors, such as reduced farm production causing depopulation of rural areas and associated weakening of traditional community ties and support ${ }^{8}$. In addition, high suicide rates among rural men (including farmers) have been linked with prevailing rural masculinity, characterised by men's traits of toughness, independence and reluctance to seek help ${ }^{10,11}$.

In response to ongoing concerns about farmer suicide, driven particularly by a series of natural disasters such as drought and flood, various mental health initiatives have been implemented in rural Australia. These initiatives generally aim to improve the detection of, and response to, mental health issues among farmers and, it is assumed, in turn reduce the high suicide rates, particularly among male farmers. One such initiative involved the development of a network of agencies working in the farming industry, to deliver mental health services based on empirical evidence about the mental health problems that farmers may be specifically likely to experience $^{12}$. However, in spite of such mental health initiatives, suicide rates among Australian farmers continue to be higher compared to the general population ${ }^{1,2,11}$. Such a high farmer suicide rate implies that farmers are a complex population requiring complex suicide prevention initiatives. Such initiatives should consider suicide risk factors that are specific for different sub-populations of farmers and go beyond a focus on mental health to encompass broader personal, situational and structural challenges faced by farmers
The available evidence on farmer suicide indicates that suicide rates and suicide risk of farmers may be affected by positionspecific (ie owner/manager versus hired worker) factors ${ }^{1}$. This research shows that farmers who are in manager positions, and die by suicide, tend to be older, and more often use firearms as a suicide method, compared to farmers who are not in owner/manager positions (eg farm labourers). Furthermore, it seems that the suicide rate of farm managers is affected more strongly by the 'health' of the agricultural industry (as indicated by the changes in the terms of trade index), compared to farm labourers ${ }^{1}$.

It is possible that apparent position-specific correlates of suicides may also be attributable to broader age differences between managers versus farm labourers; for example, older farmers may be more likely to be in owner/manager positions, and may experience different stressors to younger farmers (who may be more likely to be employed by farm managers, to do farm work). However, a study comparing younger and older male farmers (20-34 years vs $\geq 65$ years) in Iowa, USA, found that, regardless of job type, the proportion of suicides relative to employed males in general was higher among older than among younger farmers ${ }^{13}$. In contrast, a recent paper from Australia found that younger farmers ( $\leq 34$ years), both male and female, had a higher suicide rate than older farmers (aged $\geq 55$ years) ${ }^{14}$. A possible reason for the discrepancy between these two studies may be that the Iowa study considered only white (Caucasian) males, whereas the Australian study included males and females, as well as Aboriginal and Torres Strait Islander persons (who are known to have a higher suicide rate than Caucasians, especially among younger age groups $)^{15}$. However, the number of Aboriginal and Torres Strait Islander persons in the Australian study was comparatively small, and seems unlikely to offer a full explanation for the observed differences between the two studies. This highlights the importance of conducting more detailed examination of risk factors associated with suicide among farmers, across different job positions, while also controlling for age. 
While scant and in some aspects contradictory, research evidence on specific demographic and socioeconomic differences between farm managers and farm labourers nonetheless suggests that the two groups are likely to be exposed to and affected by different stressors ${ }^{1}$. However, a more comprehensive understanding of the potential differences in factors associated with suicide in farm managers relative to farm labourers, and whether differences between job positions may persist when age is controlled for, is still lacking. The aim of this article was therefore to explore whether suicide prevention for farmers may, indeed, warrant a 'job-specific' approach (or, alternatively, an 'age-specific' approach), by comparing the characteristics of suicides by farm managers with those of farm labourers in Queensland, Australia.

\section{Methods}

\section{Data sources and sample selection}

Two data sources were used to identify suicide cases among farmers: the Queensland Suicide Register (QSR), an independent database of suicide cases, and the National Coroners Information System (NCIS), an internet-based database for Australian coronial cases. Information included in the QSR is based on the police report following a possible suicide, post-mortem autopsy and toxicology report, and coroner's findings. The QSR is the only mortality database in Australia that contains comprehensive information about the demographic characteristics of the deceased, circumstances of death and a range of other events, and circumstances preceding death (eg the presence and treatment of mental illness). The information contained in the NCIS, however, is based predominantly on coronial files and includes detailed demographic characteristics of the deceased and various circumstances of death (eg location of death, method).

The NCIS was helpful in identifying suicide cases in farmers because it contains several variables (eg key words, type of occupation, location of death) that can provide an indication of whether the deceased was a farmer or not. The search in
NCIS was limited to cases with external cause of death, and was used for cross-checking the identified cases with QSR and identifying any potential 'hidden' cases. Suicide cases from both datasets were extracted if the death occurred from 2000 to 2009. Only cases classified as suicide 'beyond reasonable doubt' or 'probable' were included. Previously published literature contains more details of data sources and sample selection process $^{14,15}$.

When identifying farmers in the QSR, cases were included if their occupation at the time of death was classified as 'Farmers and farm managers' or 'Farm hands and assistants' (hereafter referred to as the 'farm managers' and 'farm labourers'). The term 'farm managers', however, may include both those who manage a farm that they own and those who are employed as managers by an external agency or organisation but do not actually own the farm. In order to identify those who were engaged in farming work only for a short time (eg holiday work), and farm work was not their usual occupation, living conditions and duration of employment at the time of death were reviewed. The term 'farm labourers' included individuals working in a range of farming-related occupations such as grazier (which is not a managing position), picker, shearer, ringer and stockman. Cases were excluded if they lived in a farming area not necessarily on the farm), but worked in an industry other than farming, or they worked in the agricultural industry, but their usual residence was elsewhere than on a farm, and where there was no evidence to indicate that they were a farmer. Examples of the latter were workers within the secondary stage of food production who deal only with the final product, but are not directly involved with primary agricultural production.

All forms of employment were included (full-time, part-time and employed with no further details on mode of employment), as well as those who were unemployed and retired. The decision to include unemployed and retired farmers was based on the concept that the occupation of a farmer includes not only the actual work but is characterised by a strong identity of farmer, living in a farming community, and rarely 'retiring' from the place of work (ie the farm and 
the stock or crops $)^{16}$. Hence, it can be assumed that categorisation of a farmer as retired or unemployed is mainly used for enumeration purposes (eg census reporting), while in everyday life, retired and unemployed farmers still live and most likely work on a farm, as well as identify themselves as farmers.

\section{Analysis}

Variables included in the analysis covered demographic characteristics (age, sex, marital status, living conditions and ethnicity status), circumstances related to death (suicide methods, suicide note), history of suicidal behaviours (communication of suicide intent and suicide attempt in lifetime and in the past 12 months) and history of physical and mental illness, including contact with health professionals prior to death, and history of problematic alcohol and drug use. The analyses also looked at the history of stressful life events, such as recent or pending unemployment and financial problems. Missing or unknown values for some variables were considered to be due to information randomly missing (rather than indicating a specific characteristic of the group). Cases with such values were therefore excluded. Data were analysed using the Statistical Package for the Social Sciences v19 (SPSS; http://www.spss.com). Suicides by farm managers were compared to suicides by farm labourers on average age, using $t$-test for independent samples, and on all other variables, using a $\chi^{2}$ analysis. Only variables where farm managers and farm labourers differed significantly $(p<0.05)$ were included into a parsimonious two-step logistic regression, which was performed to determine whether differences persisted when age was controlled for. Step 1 included job position only, and step 2 included both job position and age at time of death.

\section{Ethics approval}

This study was approved by the Griffith University human research ethics committee (reference number OTH/04/12/HRE).

\section{Results}

Over the period 2000-2009, a total of 147 suicide cases were identified in Queensland. Of those, the farm managers group accounted for $78(53.1 \%)$ cases, and the farm labourers group for 69 (46.9\%) cases. Of the 78 farm managers cases, $72(92.3 \%)$ were male, while of the 69 farm labourers, $60(87.0 \%)$ were male $\left(\chi^{2}=1.14\right.$, degrees of freedom $(\mathrm{df})=1$, $p=0.28)$. As expected, the average age of farm managers (55.3 \pm 16.5 years) was significantly higher than that of farm labourers $(35.2 \pm 13.9$ years $)\left(t_{(145)}=7.9, p<0.01\right)$. Regarding employment status, 120 farmers were employed at the time of death (60 farm managers and 60 farm labourers), 9 were unemployed (2 farm managers and 7 farm labourers), and 15 were retired ( 14 farm managers and 1 farm labourer). For three cases, the status of employment was unknown.

The most prevalent suicide method among farm managers was the use of firearms $(51.3 \%)$, which was more common compared to farm labourers $(27.5 \%) \quad\left(\chi^{2}=8.59, \mathrm{df}=1\right.$, $p<0.01)$. In contrast, hanging was more prevalent among farm labourers $(49.3 \%)$ than farm managers $(25.6 \%)$ $\left(\chi^{2}=8.80, \mathrm{df}=1, p^{<0.01}\right)$, as was toxicity due to carbon monoxide $(11.6 \%$ vs $2.6 \%)\left(\chi^{2}=4.71, \mathrm{df}=1, p=0.03\right)$.

Table 1 shows that farm managers were more often married or in a de-facto relationship, lived with their spouses (as opposed to alone), and were more often of non-Indigenous ethnicity compared to farm labourers. Considering physical and mental health, farm managers more often had at least one physical and at least one mental illness. They had also been more often in contact with a mental health professional in the past 3 months prior to death and treated for their mental illness than farm labourers. However, farm labourers had significantly more frequent problematic alcohol and drug use compared to farm managers (Table 1).

Furthermore, while exposure to most stressful life events overall was similarly frequent for both groups (Table 2), farm labourers experienced 3.1 times more likely a relationship breakdown or separation, and were 4.5 times more 
frequently exposed to recent or pending unemployment, compared to the experiences of these two events among farm managers.

Logistic regression indicated that, when age was controlled for, differences in psychiatric history variables remained apparent between the two groups (managers vs labourers). However, few life event differences persisted between the two different job position groups when age was taken into account. The exception to this was in regard to recent or pending unemployment, with farm labourers continuing to be more likely to experience this event relative to farm managers. Table 3 summarises the regression results. Interpretative caution is necessary, given the relatively low sample sizes and wide confidence intervals obtained.

\section{Discussion}

In trying to understand factors driving the elevated suicide rates among farmers, studies have typically considered farmers as a homogenous group, often neglecting potential differences in this population, such as job status and age group. The results of this study show that suicide of farmers in different job positions appears to be related to a combination of position- and age-specific factors. These findings imply that suicide prevention initiatives in farming communities should be tailored to at least two subgroups of farmers, farm managers and farm labourers, as these groups are likely to experience different suicide risk factors.

Farm labourers were around three times as likely as farm managers who died by suicide to be divorced or separated; this demographic observation was also reflected in the experience of stressful life events among farm labourers. While the relatively small sample did not allow for regression analysis controlling for both age and marital status, when age was controlled for the job-position difference in the experience of relationship breakdown became not statistically significant. This implies that the difference between farm labourers and farm managers in exposure to this event may be more strongly related to the age of farm labourers than to their job position per se. However, it is also important to note that one specific job-position factor more commonly found among farm labourers irrespective of age - the experience of recent or pending unemployment (or potentially even unstable employment) - may contribute to relationship breakdown ${ }^{17}$.

These observations are important to consider when planning suicide prevention initiatives for farmers. Empirical evidence shows that relationship separation is an important suicide risk factor in overall population, particularly in males, and can lead to various other adverse life events, such as moving residence, child custody disputes, and financial or legal issues ${ }^{18,19}$. While the stress of unemployment and relationship breakdown realistically cannot be eliminated from people's lives, strengthening an individual's personal resources, such as self-esteem, self-efficacy and locus of control, may present an important component of suicide prevention programs for farmers. In this way, farmers may feel less helpless and more equipped to cope with periods of job insecurity or the aftermath of a relationship breakdown.

Compared to farm managers, labourers were also more often single, and more often lived alone. While this may simply reflect the typical life course of younger males, future research could examine potential reasons for the apparent absence of a significant intimate relationship among many farm labourers; for example, this result may be due to financial instability, related to the parttime/sessional positions, which may delay forming stable relationships; a lack of women in the farming industry; perhaps the outward migration of women from rural areas; or, most likely, a combination of these reasons. Unsurprisingly, the male-to-female ratio among farming populations in Queensland is more than twice as high as that in the overall population ${ }^{20}$. With the background of both geographic isolation and depopulation of rural areas, the unfavourable male-to-female ratio may, through a limited mate choice, represent an important risk factor, particularly for younger farm labourers ${ }^{8}$. It could be hypothesised that younger labourers who not only are affected by financial instability, but also have a smaller chance to find a partner who could provide them support in times of financial hardships, respond to these challenging living circumstances with dysfunctional behaviours, such as alcohol and drug use. 
Table 1: Characteristics of suicides by farm managers and farm labourers, 2000-2009

\begin{tabular}{|c|c|c|c|c|c|c|c|}
\hline \multirow[t]{2}{*}{ Characteristic/event } & \multicolumn{2}{|c|}{$\begin{array}{c}\text { Farmers } / \text { farm } \\
\text { managers }(N=78)\end{array}$} & \multicolumn{2}{|c|}{$\begin{array}{c}\text { Farm } \\
\text { hands /labourers } \\
(N=69)\end{array}$} & \multirow[t]{2}{*}{$\chi^{2}$} & \multirow[t]{2}{*}{ df } & \multirow[t]{2}{*}{$P$ value } \\
\hline & $N$ & $\%$ & $N$ & $\%$ & & & \\
\hline \multicolumn{8}{|l|}{ Sex } \\
\hline Male & 72 & 92.3 & 60 & 87.0 & 1.14 & 1 & 0.28 \\
\hline Female & 6 & 7.7 & 9 & 13.0 & & & \\
\hline \multicolumn{8}{|l|}{ Marital status $^{\dagger}$} \\
\hline Married/de facto & 52 & 66.7 & 20 & 30.8 & 23.34 & 3 & $0.00 *$ \\
\hline Single/never married & 10 & 12.8 & 26 & 40.0 & & & \\
\hline Divorced/separated & 12 & 15.4 & 18 & 27.7 & & & \\
\hline Widowed & 4 & 5.1 & 1 & 1.5 & & & \\
\hline \multicolumn{8}{|l|}{ Living arrangements $^{\dagger}$} \\
\hline With spouse & 44 & 61.1 & 12 & 19.7 & 27.35 & 5 & $0.00 *$ \\
\hline With friends/other shared & 11 & 15.3 & 13 & 21.3 & & & \\
\hline With parents & 5 & 6.9 & 9 & 14.8 & & & \\
\hline Alone & 10 & 13.9 & 21 & 34.4 & & & \\
\hline Temporarily away from home & 2 & 2.8 & 6 & 9.8 & & & \\
\hline \multicolumn{8}{|l|}{ Ethnicity $^{\dagger}$} \\
\hline Aboriginal/Torres Strait Islander (ATSI) & 1 & 1.3 & 10 & 14.5 & 8.82 & 1 & $0.00 *$ \\
\hline Non-ATSI & 74 & 98.7 & 59 & 85.5 & & & \\
\hline \multicolumn{8}{|l|}{ Expressions of suicidality } \\
\hline Communicated suicide intent in lifetime & 36 & 46.2 & 32 & 46.4 & 0.00 & 1 & 0.99 \\
\hline Communicated suicide intent in past 12 months & 30 & 38.5 & 31 & 44.9 & 0.63 & 1 & 0.43 \\
\hline Suicide attempt in lifetime & 12 & 15.4 & 15 & 21.7 & 0.99 & 1 & 0.32 \\
\hline Suicide attempt in past 12 months & 7 & 9.0 & 7 & 10.1 & 0.06 & 1 & 0.81 \\
\hline Suicide note & 28 & 35.9 & 19 & 27.5 & 1.18 & 1 & 0.28 \\
\hline \multicolumn{8}{|l|}{ Physical and mental illness } \\
\hline Physical illness (at least one) & 32 & 41.0 & 14 & 20.3 & 7.32 & 1 & $0.01 *$ \\
\hline Diagnosed mental illness (at least one) & 40 & 51.3 & 17 & 24.6 & 10.95 & 1 & $0.00 *$ \\
\hline Untreated (suspected) mental illness & 17 & 21.8 & 14 & 20.3 & 0.05 & 1 & 0.82 \\
\hline Contact with a doctor for a physical condition & 20 & 25.6 & 14 & 21.2 & 0.39 & 1 & 0.53 \\
\hline $\begin{array}{l}\text { Contact with a mental health professional for psychiatric } \\
\text { condition (last } 3 \text { months) }\end{array}$ & 32 & 41.0 & 12 & 17.4 & 9.75 & 1 & $0.00 *$ \\
\hline Current or past treatment for psychiatric condition & 42 & 53.8 & 19 & 28.8 & 9.19 & 1 & $0.00 *$ \\
\hline \multicolumn{8}{|l|}{ Problematic alcohol use } \\
\hline Yes & 5 & 6.4 & 17 & 24.6 & 9.56 & 1 & $0.00 *$ \\
\hline No/unknown & 73 & 93.6 & 52 & 75.4 & & & \\
\hline \multicolumn{8}{|l|}{ Illicit drug use } \\
\hline Yes & 6 & 7.7 & 23 & 33.3 & 15.20 & 1 & $0.00 *$ \\
\hline No/unknown & 72 & 92.3 & 46 & 66.7 & & & \\
\hline \multicolumn{8}{|l|}{ Prescription drug use } \\
\hline Yes & 0 & - & 1 & 1.4 & 1.14 & 1 & 0.29 \\
\hline No/unknown & 78 & 100.0 & 68 & 98.6 & & & \\
\hline
\end{tabular}


Table 2: Life events history of farm managers and farm labourers, 2000-2009

\begin{tabular}{|c|c|c|c|c|c|c|c|}
\hline \multirow[t]{2}{*}{ Characteristic/event } & \multicolumn{2}{|c|}{$\begin{array}{c}\text { Farmers/farm } \\
\text { managers }(N=78)\end{array}$} & \multicolumn{2}{|c|}{$\begin{array}{l}\text { Farm hands / labourers } \\
\qquad(N=69)\end{array}$} & \multirow[b]{2}{*}{$\chi^{2}$} & \multirow[b]{2}{*}{ dff } & \multirow[b]{2}{*}{$p$ value } \\
\hline & $N$ & $\%$ & $N$ & $\%$ & & & \\
\hline \multicolumn{8}{|l|}{ Any life event } \\
\hline Yes & 71 & 91.0 & 59 & 85.5 & 1.090 & 1 & 0.296 \\
\hline No/unknown & 7 & 9.0 & 10 & 14.5 & & & \\
\hline \multicolumn{8}{|c|}{ Relationship breakdown, separation } \\
\hline Yes & 9 & 11.5 & 25 & 36.2 & 12.556 & 1 & $0.000 *$ \\
\hline No & 69 & 88.5 & 44 & 63.8 & & & \\
\hline \multicolumn{8}{|l|}{ Relationship conflict } \\
\hline Yes & 10 & 12.8 & 9 & 13.0 & 0.002 & 1 & 0.968 \\
\hline No & 68 & 87.2 & 60 & 87.0 & & & \\
\hline \multicolumn{8}{|c|}{ Conflict with other persons } \\
\hline Yes & 5 & 6.4 & 10 & 14.5 & 2.610 & 1 & 0.106 \\
\hline No & 73 & 93.6 & 59 & 85.5 & & & \\
\hline \multicolumn{8}{|l|}{ Bereavement } \\
\hline Yes & 8 & 19.3 & 9 & 13.0 & 0.278 & 1 & 0.598 \\
\hline No & 70 & 89.7 & 60 & 87.0 & & & \\
\hline \multicolumn{8}{|l|}{ Pending legal matters } \\
\hline Yes & 7 & 9.0 & 12 & 17.4 & 2.305 & 1 & 0.129 \\
\hline No & 71 & 91.0 & 57 & 82.6 & & & \\
\hline \multicolumn{8}{|c|}{ Recent/pending unemployment } \\
\hline Yes & 2 & 2.6 & 8 & 11.6 & 4.709 & 1 & $0.030 *$ \\
\hline No & 76 & 97.4 & 61 & 88.4 & & & \\
\hline \multicolumn{8}{|l|}{ Financial problems } \\
\hline Yes & 14 & 17.9 & 8 & 11.6 & 1.162 & 1 & 0.281 \\
\hline No & 64 & 82.1 & 61 & 88.4 & & & \\
\hline \multicolumn{8}{|l|}{ Work/school problems } \\
\hline Yes & 14 & 17.9 & 7 & 10.1 & 1.821 & 1 & 0.177 \\
\hline No & 64 & 82.1 & 62 & 89.9 & & & \\
\hline
\end{tabular}

* Statistical significance at $p=0.05$ level.

$\mathrm{df}$, degrees of freedom

Table 3: Summary of logistic regression analysis for variables distinguishing between suicide of farm managers and farm labourers, with age as a control variable

\begin{tabular}{|c|c|c|c|c|}
\hline \multirow[t]{2}{*}{ Characteristic/event } & \multicolumn{2}{|c|}{ Step 1: Job position } & \multicolumn{2}{|c|}{ Step 2: Job position and age } \\
\hline & Odds ratio & $95 \% \mathrm{CI}$ & Odds ratio & $95 \% \mathrm{CI}$ \\
\hline Physical illness (at least one) & $0.37 * *$ & $0.17-0.77$ & 1.19 & $0.47-3.04$ \\
\hline Diagnosed mental illness (at least one) & $0.31 * *$ & $0.15-0.63$ & $0.36 *$ & $0.16-0.82$ \\
\hline $\begin{array}{l}\text { Contact with a mental health professional for psychiatric } \\
\text { condition (last } 3 \text { months) }\end{array}$ & $0.30 * *$ & $0.14-0.65$ & $0.38 *$ & $0.15-0.92$ \\
\hline Current or past treatment for psychiatric condition & $0.35 * *$ & $0.17-0.69$ & $0.34 * *$ & $0.15-0.78$ \\
\hline Problematic alcohol use & $4.77 * *$ & $1.66-13.76$ & 3.25 & $0.97-10.97$ \\
\hline Illicit drug use & $6.00 * *$ & $2.27-15.85$ & 2.68 & $0.89-8.03$ \\
\hline Relationship breakdown, separation & $4.36 * *$ & $1.86-10.20$ & 2.57 & $0.97-6.86$ \\
\hline Recent/pending unemployment & $4.98 *$ & $1.02-24.33$ & $7.88 *$ & $1.22-50.84$ \\
\hline
\end{tabular}

Job position reference group: managers

$* p<0.05, * * p<0.01$

CI, confidence interval 
The profiles of farm labourers who died by suicide were characterised by more frequent problematic use of alcohol and drugs compared to farm managers. However, this difference disappeared when controlling for age, suggesting in similar fashion to the observations about relationship difficulties - that farm labourers may be more likely to exhibit this characteristic due to their generally younger age, rather than their job position as such. The relatively higher use of alcohol among farm labourers who died by suicide is noteworthy also from the perspective of preventing other types of injuries, given that the impact of alcohol in explaining socioeconomic differentials between upper nonmanual employees and manual workers in both accidental and violent deaths is substantial ${ }^{21}$. In the context of evidence on the importance of alcohol use for suicide and non-suicide mortality risk among farmers ${ }^{13,22}$ the findings of this study additionally underline the need for strategies, policies and services that would reduce the consumption of alcohol, and also drugs, among young farmers in general and young farm labourers in particular.

It is noteworthy that farm managers who died by suicide had significantly more often at least one physical or diagnosed mental illness at the time of death, and were also more often treated by and in contact with a mental health professional shortly prior to death, compared to farm labourers. These differences persisted when age was controlled for. Given the limitations in analysis, this may indicate an influence of job position or, potentially, be a reflection of the differences in marital status between farm managers and farm labourers; for example, managers may be more likely to seek help because they are more likely to have a spouse, who may in turn encourage help-seeking behaviour. This finding has at least two implications. First, it provides empirical evidence to inform existing suicide prevention initiatives for farmers ${ }^{12}$, by highlighting the need for more sensitive suicide assessment of farm managers who have either physical or mental illness (or both) ${ }^{23}$. Specifically, the support and assistance to farmers at increased risk of suicide would need to be both appropriate to the agricultural context (eg consider specific farming-related stressors and circumstances) and provided in a manner that is acceptable for farmers (eg considering the cultural context with prevailing masculine and stoic culture). Second, the lower levels of contact with mental health professionals among farm labourers, coupled with an absence of significant differences in levels of untreated mental illness between farm labourers and managers, appears to indicate that farm labourers may experience a somewhat different set of suicide risk factors to those of farm managers.

The types of risk factors for farm labourers may include such issues as relationship stress, lack of support networks, low integration into the community and substance misuse ${ }^{24}$. A possible community-based initiative for farm labourers at suicide risk, which would consider the apparently relatively small prevalence of physical and mental illness in this subgroup, could be creation of a 'buddy system'. This type of initiative engages the so-called 'emergent' gatekeepers, that is, community members or occupations that have not been formally trained to intervene with someone at risk of suicide, but are likely to come into contact with at-risk individuals ${ }^{25}$. Gatekeeper education has been suggested as effective in suicide prevention, and has been implemented in other at-risk, male-dominated occupations ${ }^{26,27}$.

Furthermore, given that in the current study, pending or actual job unemployment was relatively frequent in farm labourers, suicide prevention programs could be extended beyond mental health services. In this way, other service providers such as financial and employment advisers, could enable such providers to more effectively link farmers into a supportive network with more specialised services to assist them, which might be particularly relevant for younger farm labourers who are at greater risk of unemployment ${ }^{12}$.

Actively involving farm labourers in suicide prevention may be effective in reducing the risk of suicide in the context of the relatively common experience of pending or recent unemployment in this subgroup. In this way, farm labourers could be trained to pay particular attention to the wellbeing of other farm labourers, who due to the nature of their work/working conditions may be likely to be the first 
workers to be made redundant in times of financial hardship in the agricultural sector. To develop suicide prevention programs for farm labourers that would appreciate their personal experiences and perspectives around suicide, future studies might need to employ qualitative methods to extend knowledge about effective suicide prevention initiatives for this at-risk group. Such knowledge might help to understand how various risk factors such as relationship stress, pending unemployment and substance misuse interact with each other, and, based on that, design appropriate interventions.

It is also reasonable to make the observation that many of the risk factors observed in this study are found among other atrisk populations, irrespective of the industry of employment, rather than being unique to the farming population. In addition, there remain notable gaps in knowledge about types of suicide prevention initiatives that are most effective in targeting these risk factors. Although the current study provides new insights into risk factors among a specific highrisk group, policy and program development clearly requires a more detailed and comprehensive evidence base if it is to be adequately informed, and the interventions suggested above should be viewed in this context.

In addition to the demographic and health-related differences between farm managers and farm labourers discussed above, the two groups in this study differed in the most prevalent suicide method. The use of firearms among on-average older farm managers is consistent with a previous study in Queensland, noting that firearms as a means of suicide were more likely to be used among older men in remote or very remote localities ${ }^{28}$. The same study showed that the choice of a suicide method is affected not only by the availability of suicide means, but also by age and location, which is in line with the use of hanging over firearms among farm labourers observed in this study. Indeed, hanging has been observed to be increasing among young males in the general population $^{29}$. Given that applying a strategy such as restriction of means in preventing suicides by hanging is practically impossible (as there are numerous means that can be used to hang oneself), younger farm labourers may require other, more targeted suicide prevention approaches (ie for individuals who are at potential or high risk).

\section{Limitations}

There is a possibility that some of the observed differences in this study may simply reflect general, community-level differences between age groups, irrespective of occupation, or also that the observed characteristics may be similar to the ones leading to suicide in the general population. Future studies could, therefore, compare an age-matched sample of farmers and non-farmers who died by suicide, in order to further distinguish between the effects of the occupation and the effect of age, and also to compare farmers who died by suicide with living controls to identify any characteristics that may be unique to farmers who die by suicide. In addition, small sample numbers of retired and unemployed farmers, and also females in the current study precluded more detailed analysis on any of these subsamples. Future research might want to replicate this study on a larger sample to better understand suicidal behaviour within these subgroups. Better recording of the job type (eg principal farmer, spouse, salaried/employed manager vs owner/farm manager, regular hired worker and seasonal/hired worker) in mortality databases may help to identify other potential job-specific risk and protective factors of suicide in farmers, to plan more tailored suicide-prevention initiatives in this high-risk occupation group ${ }^{30}$.

\section{Conclusions}

The results of this study imply that suicide prevention strategies should take into account factors associated specifically with job position - such as recent or pending unemployment among labourers - as well as certain demographic characteristics and stressful life events which may be more strongly related to age than job position, such as relationship breakdown among younger male farmers and physical illness among older male farmers. Overall, the study suggests that suicide risk among farm labourers may be associated with being younger, single or divorced/separated, 
living alone, and using alcohol and drugs more often than older farmers, as well as experiencing factors that may affect their integration into the community, such as job insecurity ${ }^{24}$. In contrast, farm managers may be exposed to a different set of factors that contribute to their vulnerability to suicide, such as physical and mental illness, which opens a venue for detection and intervention points at both physical health and mental health services.

\section{Acknowledgements}

The authors gratefully thank Queensland Health/Queensland Mental Health Commission for their continuing support of the Queensland Suicide Register and acknowledge funding from the Australian Research Council (project no. LP1201000021).

\section{References}

1. Page AN, Fragar LJ. Suicide in Australian farming, 1988-1997. Australasian Psychiatry 2002; 36(1): 81-86.

2. Andersen K, Hawgood J, Klieve H, Kõlves K, De Leo D. Suicide in selected occupations in Queensland: evidence from the State suicide register. Australian and New Zealand Journal of Psychiatry 2010; 44(3): 243-252.

3. Stallones L. Suicide mortality among Kentucky farmers, 19791985. Suicide and Life-Threatening Behavior 1990; 20(2): 156-163.

4. Meneghel SN, Victora CG, Faria N, de Carvalho LA, Falk JW. Epidemiological aspects of suicide in Rio Grande do Sul, Brazil. Revista de Saúde Pública 2004; 38(6): 804-810.

5. Kelly S, Charlton J, Jenkins R. Suicide deaths in England and Wales, 1982-92: the contribution of occupation and geography. Population Trends 1995; 80: 16-25.

6. Patel V, Ramasundarahettige C, Vijayakumar L, Thakur JS, Gajalakshmi V, Gururaj G, et al. Suicide mortality in India: a nationally representative survey. Lancet 2012; 379(9834): 2343-2351.
7. Gallagher LM, Kliem C, Beautrais AL, Stallones L. Suicide and occupation in New Zealand, 2001-2005. International Journal of Occupational and Environmental Health 2008; 14(1): 45-50.

8. Hirsch JK. A review of the literature on rural suicide. Crisis: The Journal of Crisis Intervention and Suicide Prevention 2006; 27(4): 189199.

9. Fraser CE, Smith KB, Judd F, Humphreys JS, Fragar LJ, Henderson A. Farming and mental health problems and mental illness. International Jounral of Social Psychiatry 2005; 51(4): 340349 .

10. O'Kane G, Craig P, Sutherland D. Riverina men's study: an exploration of rural men's attitudes to health and body image. Nutrition \& Dietetics 2008; 65(1): 66-71.

11. Alston M. Rural male suicide in Australia. Social Science \& Medicine 2012; 74(4): 515-522.

12. Fragar LJ, Kelly B, Peters M, Henderson A, Tonna A. Partnerships to promote mental health of NSW farmers: the New South Wales Farmers Blueprint for Mental Health. Australian Journal of Rural Health 2008; 16(3): 170-175.

13. Zwerling C, Burmeister LF, Jensen CM. Injury mortality among Iowa farmers, 1980-1988: comparison of PMR and SMR approaches. American Journal of Epidemiology 1995; 141(9): 878-882.

14. Arnautovska U, McPhedran S, De Leo D. A regional approach to understanding farmer suicide rates in Queensland. Social Psychiatry and Psychiatric Epidemiology 2013; 49(4): 593-599.

15. De Leo D, Sveticic J, Kumpula EK. Suicide in Queensland 20082010. Mortality rates and related data. Brisbane: Australian Institute for Suicide Research and Prevention 2013.

16. Burton RJF. Seeing through the 'good farmer's' eyes: towards developing an understanding of the social symbolic value of 'productivist' behaviour. Sociologia Ruralis 2004; 44(2): 195-215. 
17. Kitson GC, Babri KB, Roach MJ. Who divorces and why: a review. Journal of Family Issues 1985; 6(3): 255-293.

18. Ide N, Wyder M, Kolves K, De Leo D. Separation as an important risk factor for suicide: a systematic review. Journal of Family Issues 2010; 31(12): 1689-1716.

19. Sweeper S, Halford K. Assessing adult adjustment to relationship separation: the Psychological Adjustment to Separation Test (PAST). Journal of Family Psychology 2006; 20(4): 632-640.

20. Australian Bureau of Statistics. 2006 Table Builder. (Online) 2006. Available: http://www.abs.gov.au/tablebuilder (Accessed 3 September 2013).

21. Mäkelä P, Valkonen T, Martelin T. Contribution of deaths related to alcohol use of socioeconomic variation in mortality: register based follow up study. British Medical Journal 1997; 315(7102): 211-217.

22. Milner A, De Leo D. Suicide by motor vehicle "accident" in Queensland. Traffic Injury Prevention 2012; 13(4): 342-349.

23. Kavalidou K, McPhedran S, De Leo D. Farmers' contact with healthcare services prior to suicide: evidence for the role of general practitioners as an intervention point. Australian Journal of Primary Health 2013; 21(1): 102-105.
24. Stafford MC, Gibbs JP. A major problem with the theory of status integration and suicide. Social Forces 1985; 63(3): 643-660.

25. Isaac M, Elias B, Katz LY, Belik SL, Deane FP, Enns MW, et al. Gatekeeper training as a preventative intervention for suicide: a systematic review. Canadian Journal of Psychiatry 2009; 54(4): 260268 .

26. Beautrais A, Fergusson D, Coggan C, Collings C, Doughty C, Ellis $\mathrm{P}$, et al. Effective strategies for suicide prevention in New Zealand: a review of the evidence. New Zealand Medical Journal 2007; 120(1251): U2459.

27. MATES in Construction. MATES in Construction. (Online) 2011. Available: http://www.matesinconstruction.org.au (Accessed 16 July 2013).

28. Klieve H, Sveticic J, De Leo D. Who uses firearms as a means of suicide? A population study exploring firearm accessibility and method choice. BMC Medicine 2009; 7(1): 52.

29. De Leo D, Dwyer J, Firman D, Neulinger K. Trends in hanging and firearm suicide rates in Australia: substitution of method? Suicide and Life-Threatening Behavior 2003; 33(2): 151-64.

30. Thomas HV, Lewis G, Thomas D, Salmon RL, Chalmers RM, Coleman TJ, et al. Mental health of British farmers. Occupational and Environmental Medicine 2003; 60(3): 181-186. 